\title{
Estimating the Effect of Social Distancing Interventions on COVID-19 in the United States
}

\author{
Andrew M. Olney \\ University of Memphis \\ aolney@memphis.edu \\ Fridtjof Thomas \\ University of Tennessee \\ fthomas4@uthsc.edu
}

\author{
Jesse Smith \\ Innovate Memphis \\ jessesmith96.js@gmail.com \\ H. Juliette T. Unwin \\ Imperial College London \\ h.unwin@imperial.ac.uk
}

\author{
Saunak Sen \\ University of Tennessee \\ sen@uthsc.edu
}

\begin{abstract}
Since its global emergence in 2020, severe acute respiratory syndrome coronavirus 2 (SARS-CoV-2) has caused multiple epidemics in the United States. Because medical treatments for the virus are still emerging and a vaccine is not yet available, state and local governments have sought to limit its spread by enacting various social distancing interventions such as school closures and lockdown, but the effectiveness of these interventions is unknown. We applied an established, semi-mechanistic Bayesian hierarchical model of these interventions on SARS-CoV-2 spread in Europe to the United States. We estimated the effect of interventions across all states, contrasted the estimated reproduction number, $\mathrm{R}_{\mathrm{t}}$, for each state before and after lockdown, and contrasted predicted future fatalities with actual fatalities as a check on the model's validity. Overall, school closures and lockdown are the only interventions modeled that have a reliable impact on $R_{t}$, and lockdown appears to have played a key role in reducing $R_{t}$ below 1.0. We conclude that reversal of lockdown, without implementation of additional, equally effective interventions, will enable continued, sustained transmission of SARS-CoV-2 in the United States.
\end{abstract}

Keywords: Bayesian hierarchical model, intervention, severe acute respiratory syndrome coronavirus 2, social distancing, time-varying reproduction number

\section{INTRODUCTION}

Severe acute respiratory syndrome coronavirus 2 (SARS-CoV-2) causes coronavirus disease 2019 (COVID-19). Initially discovered in Wuhan, China in December 2019, SARS-CoV-2 rapidly spread to the rest of the world, initially through travelers from Wuhan, but later through community transmission in Asia, Europe, Australia, and North America, until it was declared a pandemic by the World Health Organization on March 11, 2020. The rapid spread of SARSCoV-2 is attributable to its transmissibility by aerosol and fomites (van Doremalen et al., 2020; Bourouiba, 2020), by presymptomatic/asymptomatic carriers (Bai et al., 2020; Furukawa et al., 2020), and by the relatively mild clinical characteristics of symptomatic carriers, which often include fever, cough, and fatigue (Guan et al., 2020). However, approximately $20 \%$ of confirmed 
medRxiv preprint doi: https://doi.org/10.1101/2020.07.10.20151001; this version posted July 11, 2020. The copyright holder for this preprint

(which was not certified by peer review) is the author/funder, who has granted medRxiv a license to display the preprint in perpetuity.

It is made available under a CC-BY-NC-ND 4.0 International license .

cases develop severe or critical forms of COVID-19, including complications of respiratory failure, myocardial dysfunction, and acute kidney injury, with approximiately $50 \%$ mortality for critically-ill patients (Phua et al., 2020).

As of July 2020, outbreaks or epidemics of SARS-CoV-2 have emerged in all 50 states, with over 2.5 million confirmed cases reported. Because medical treatments for and vaccinations against the virus are still emerging, state and local governments have sought to limit its spread by enacting various social distancing interventions. Social distancing interventions have varied widely both within states and across states. Within states, interventions typically have begun with public health directives like washing hands and staying home if sick, followed by restrictions on or closures of places housing vulnerable populations like nursing homes or schools, followed by successive, increasingly restrictive bans on gathering in groups, culminating in stay-at-home orders or so-called lockdown. Across states, interventions have been adopted with different speeds, such that some states moved rapidly to lockdown and other states never entered lockdown at all. Likewise, states are currently lifting lockdown and reversing social distancing interventions at different rates.

To explore the effect of social distancing interventions, we applied an established, semimechanistic Bayesian hierarchical model of these interventions on SARS-CoV-2 spread in Europe (Flaxman et al., 2020a; Flaxman et al., 2020b) to the United States. We estimated the effect of interventions and the time-varying reproduction number $\left(\mathrm{R}_{\mathrm{t}}\right)$ for each state using state-level daily case fatality counts.

\section{METHODS}

\subsection{DATA}

In this study, we used data from three different sources: state-level intervention data, infection fatality rate data, and confirmed case fatality data.

STATE-LEVEL INTERVENTION DATA. We created a dataset of state-level intervention dates by inspecting the executive orders, public health directives, and official communications (e.g., press releases) from state governments (Olney and Olney, 2020). For each intervention date, we used the effective date, unless the timing of the intervention was so close to midnight as to only practically have effect the next day. Interventions were only counted if they targeted the general population, e.g., restricting out-of-state travel by state employees only was not counted as a travel restriction intervention. All interventions dates are linked to their source documents with any needed commentary for data provenance. The interventions themselves closely parallel those in the European model we used, but with slightly different operationalizations which we describe in turn. Self isolating if ill is a recommendation to stay home if sick. Social distancing encouraged is a recommendation to avoid nonessential travel and/or contact; the mere words "social distancing" were not counted unless they were elaborated with examples of what social distancing entails. Schools or universities closing is the date at which schools partly or completely close; the earlier of schools or universities closing was used. Sport is the banning of sporting events or public gatherings of more than 1000 persons. Public events is the banning of public gatherings of more than 100 participants. Finally, lockdown includes banning of nonessential gatherings or business operations, which is sometimes formalized as a stay-at-home or 
safer-at-home order. Notably some more restrictive interventions imply others, e.g., lockdown implies all other interventions, and public events implies sport.

INFECTION FATALITY RATE DATA. The infection fatality rate (IFR), or ratio of fatalities to true infections, was derived via the methods outlined in Flaxman et al. Briefly, IFR estimates from Verity et al. (2020) were adjusted using an age-specific UK contact matrix to account for non-uniform attack rates across age groups (see Ferguson et al. 2020 for details and previous US application). The resulting IFRs were weighted by state-level age demographics and averaged to produce estimates adjusted for both age and location. Demographic data were obtained from the 2018 ACS survey 5-year estimates (U.S. Census Bureau, 2020).

CONFIRMED CASE FATALITY DATA. SARS-CoV-2 fatality data was obtained from the New York Times public data repository (The New York Times, 2020), which describes the data collection process along with subtle issues in counting cases, e.g. cruise ship passengers. In general, the dataset counts confirmed cases according to where they were treated. Deaths are counted on the days they were reported up to midnight Eastern Time. Because this dataset provides cumulative counts, we transformed these into daily counts by taking the difference between successive daily cumulative counts (setting this difference to zero in the rare instances where cumulative counts were decreasing due to reporting corrections).

\section{MODEL}

We applied an established, semi-mechanistic Bayesian hierarchical model of interventions on SARS-CoV-2 spread in Europe to the United States, and the design and details of this model are presented elsewhere (Flaxman et al., 2020a; Flaxman et al., 2020b). Notably, a recent variant of this model has been applied to the United States at the state level, but this variant uses mobility data rather than interventions as the basis of predictions (Unwin et al., 2020). Briefly stated, daily death counts in the model follow a negative binomial distribution such that their expectation is a function of infections on previous days. The model is semi-mechanistic in the sense that it incorporates classical Susceptible-Infected-Removed concepts (Horsburgh and Mahon, 2008) in a Bayesian framework. The number of infected is modeled using a discrete renewal process that accounts for population saturation. Death counts are similarly linked to the number of infected based on the country (or state in the present case) IFR and the distribution of times from infection to death. Importantly, the model assumes the effect of intervention is that same regardless of location and that the implementation of an intervention instantaneously reduces $\mathrm{R}_{\mathrm{t}}$. Making these assumptions allows data from multiple locations to be pooled for estimating intervention effects. The model was specified using Stan (Carpenter et al., 2017), and model inference was performed using adaptive Hamiltonian Monte Carlo. We fit our model with a time series for each state 30 days before the state has experienced seven deaths ${ }^{1}$, up to April 25, 2020, when some states began reversing their interventions.

\footnotetext{
${ }^{1}$ The Europe model used ten deaths as a somewhat arbitrary threshold for excluding imported cases; seven is the highest number we can use and still obtain valid data for states like Alaska, which have relatively low case count, cf. Unwin et al. (2020).
} 
Table 1: National intervention effects on $\mathrm{R}_{\mathrm{t}}$.

\begin{tabular}{|c|c|c|c|}
\hline \multirow[t]{2}{*}{ Intervention } & \multirow[t]{2}{*}{ Mean } & \multicolumn{2}{|c|}{$95 \% \mathrm{CI}$} \\
\hline & & LL & UL \\
\hline Self isolating if ill & .012 & .000 & .059 \\
\hline Sport & .021 & .000 & .102 \\
\hline Social distancing encouraged & .033 & .000 & .162 \\
\hline Public events & .103 & .000 & .379 \\
\hline Schools or universities closing & .271 & .007 & .518 \\
\hline Lockdown & .785 & .592 & .987 \\
\hline
\end{tabular}

Note. Abbreviations: CI, credible interval; LL, lower limit; UL, upper limit.

\section{REsults}

The mean number of days between the first and last intervention of a state was 19.53 days (SD $=5.73$, range: 8-31). While each of 50 states had the opportunity to implement six different social distancing interventions, only 289 or $96.33 \%$ were implemented, with lockdown being the least implemented $(\mathrm{n}=43)$. The mean IFR was $1.11 \%(\mathrm{SD}=.12 \%$, range: $.76-1.35 \%)$. Because confirmed case fatality data increased dramatically over the time period examined, similar statistics are not reported for these data.

Estimated national intervention effects on $R_{t}$ are shown in Table 1. Each estimated effect is an absolute reduction in $\mathrm{R}_{\mathrm{t}}$. It is evident that only schools or universities closing and lockdown have a nontrivial impact on $\mathrm{R}_{\mathrm{t}}$. Moreover, schools or universities closing and lockdown are the only interventions whose $95 \%$ credible interval does not cross zero.

State-level measures and estimates of the model are shown in Table 2. Of primary interest are the $\mathrm{R}_{\mathrm{t}}$ estimates before and after lockdown and the corresponding death counts 2 weeks into the future, which are contrasted with actual deaths to assess model validity. Notably, no state had a mean $\mathrm{R}_{\mathrm{t}}$ below 1.0 pre-lockdown, but 29 states had a $\mathrm{R}_{\mathrm{t}}$ below 1.0 after lockdown. While lockdown had a strong effect in reducing $R_{t}$ in all states that underwent lockdown, in these 29 states, lockdown appears to have been the single critical intervention allowing containment of the disease.

Predicted deaths vs. actual deaths in each state serve as a validity check on the model's estimates of intervention effects. Thirty-six states (72\%) had actual deaths that were within the $95 \%$ CI of predicted deaths. Notably, the mean predicted deaths were well above actual ( $>100$ deaths) for Connecticut, New Jersey, Massachusetts, and New York. The mean absolute error of mean predicted deaths was 50.80, and without these four states the mean absolute error was 10.08 . 
medRxiv preprint doi: https://doi.org/10.1101/2020.07.10.20151001; this version posted July 11, 2020. The copyright holder for this preprint (which was not certified by peer review) is the author/funder, who has granted medRxiv a license to display the preprint in perpetuity. It is made available under a CC-BY-NC-ND 4.0 International license .

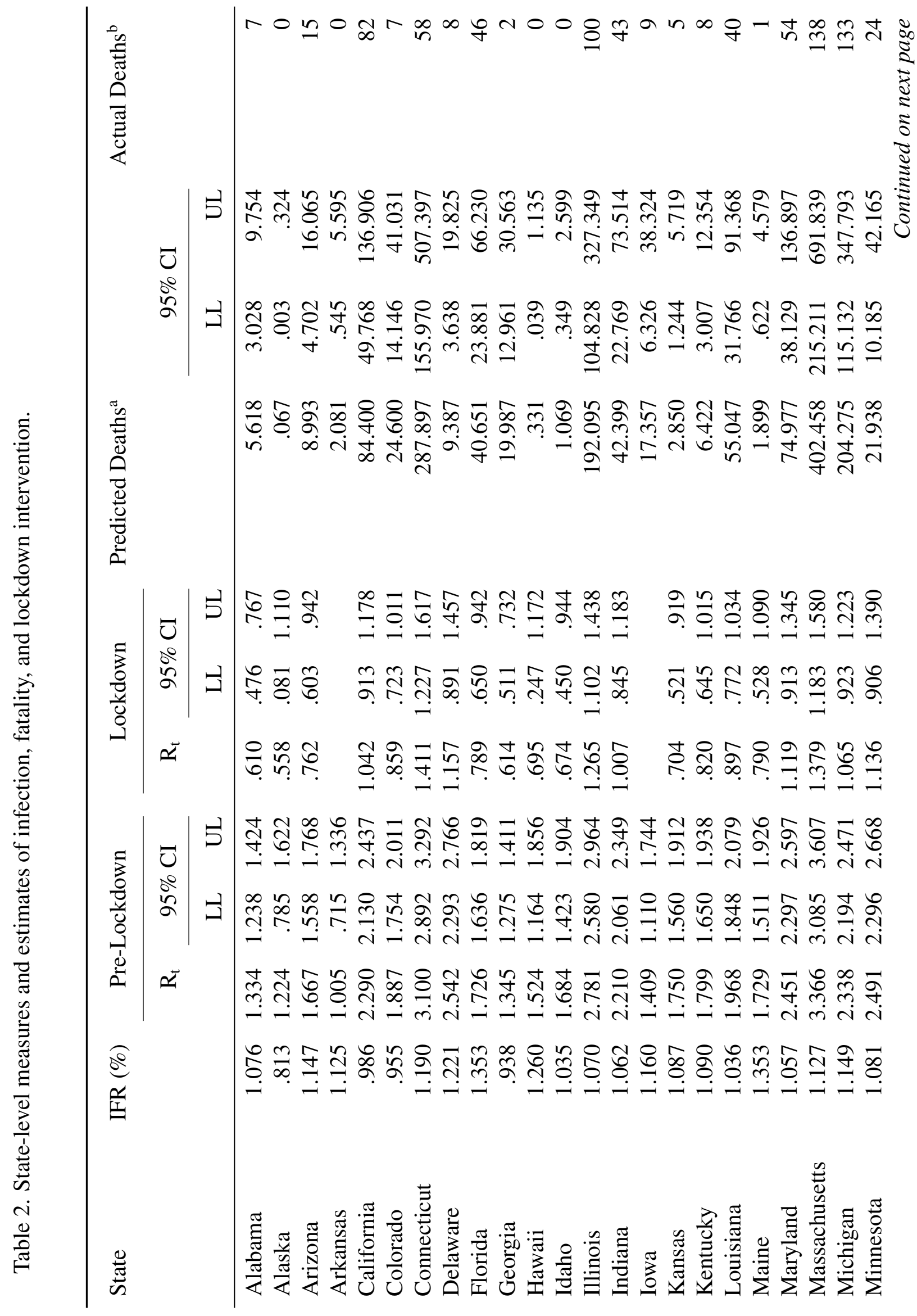


medRxiv preprint doi: https://doi.org/10.1101/2020.07.10.20151001; this version posted July 11, 2020. The copyright holder for this preprint (which was not certified by peer review) is the author/funder, who has granted medRxiv a license to display the preprint in perpetuity. It is made available under a CC-BY-NC-ND 4.0 International license .

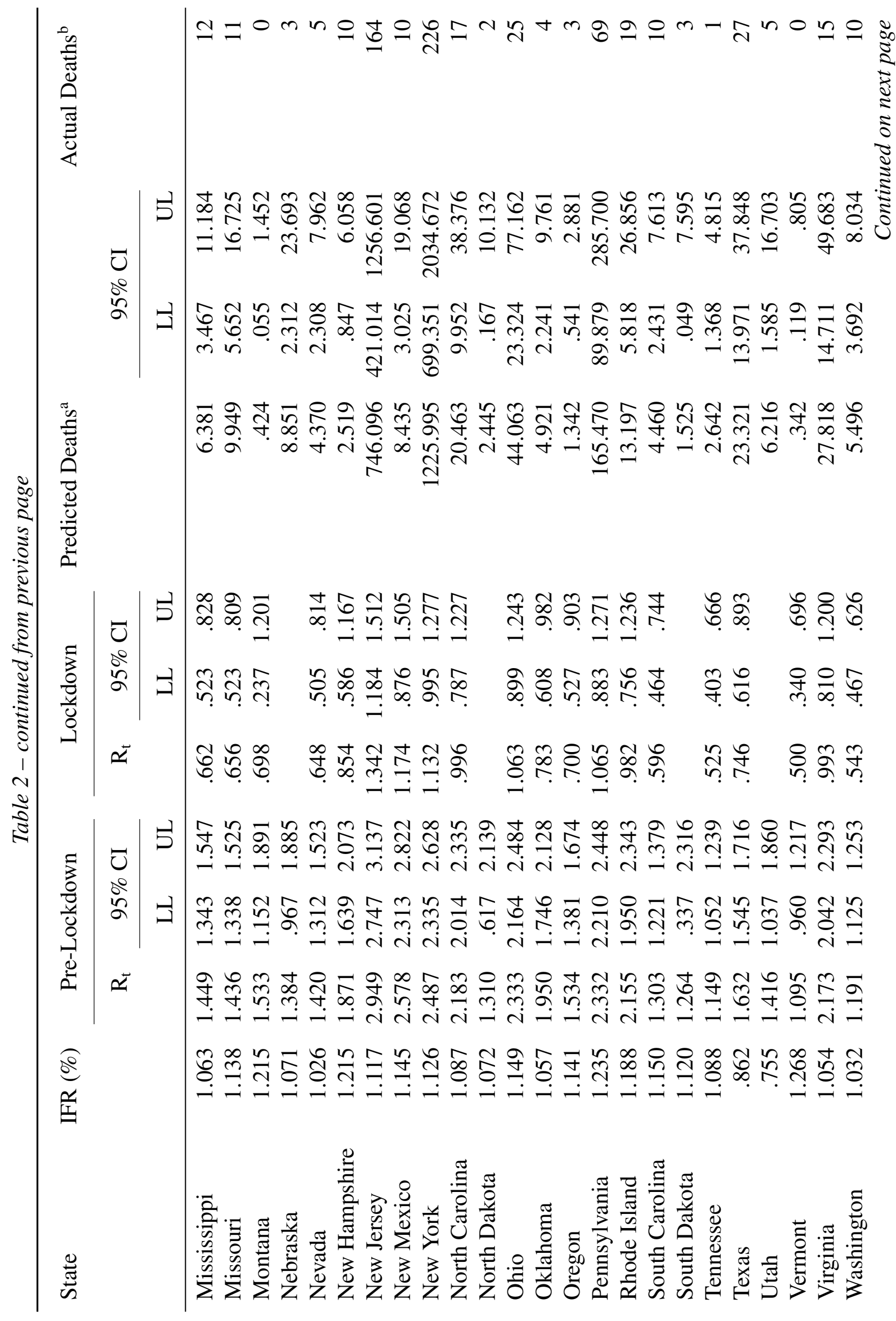




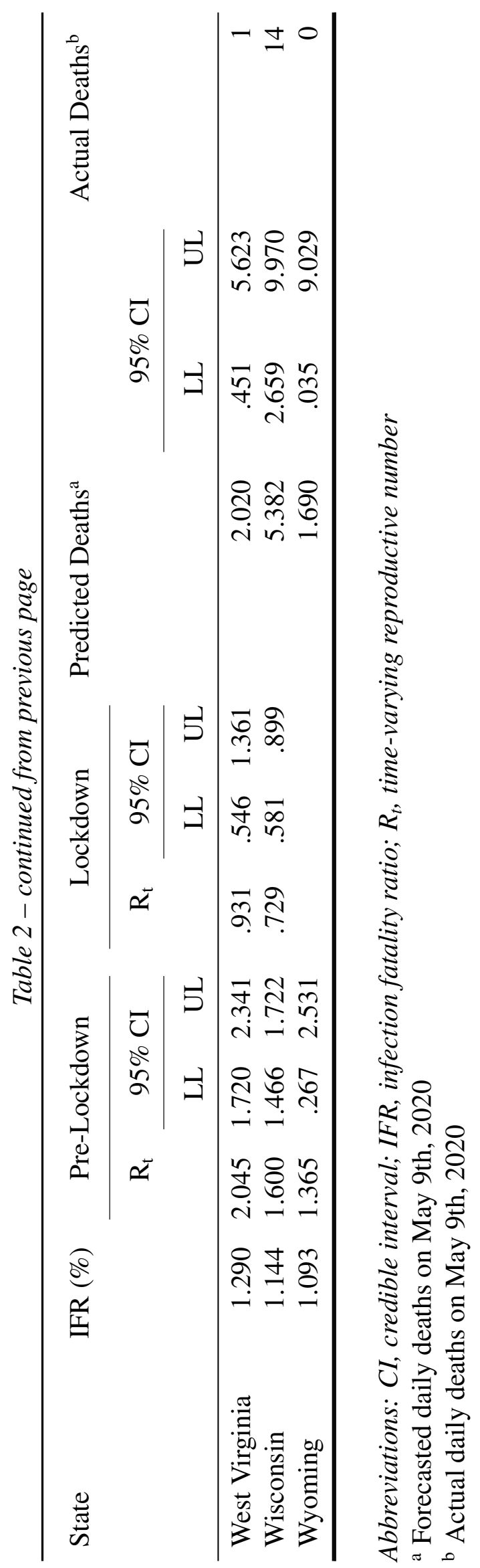


medRxiv preprint doi: https://doi.org/10.1101/2020.07.10.20151001; this version posted July 11, 2020. The copyright holder for this preprint

(which was not certified by peer review) is the author/funder, who has granted medRxiv a license to display the preprint in perpetuity.

It is made available under a CC-BY-NC-ND 4.0 International license .

\section{DISCUSSION}

Social distancing interventions are important for limiting the spread of SARS-CoV-2, because medical treatments for COVID-19 are still emerging and a vaccine is not available. To our knowledge, we are the first to apply an established, semi-mechanistic Bayesian hierarchical model of these interventions on SARS-CoV-2 spread in Europe to the United States. We estimated the effect of interventions across all states, contrasted the estimated $\mathrm{R}_{\mathrm{t}}$ for each state before and after lockdown, and contrasted predicted future fatalities with actual fatalities as a check on the model's validity. Overall, school closures and lockdown orders are the only interventions modeled that have an estimated effect where the $95 \%$ credible interval does not include zero, i.e. no effect. No state had an estimated $R_{t}$ below 1.0 before lockdown, but 29 states reached an $\mathrm{R}_{\mathrm{t}}$ below 1.0 after lockdown. The model's ability to successfully predict future deaths supports the validity of estimated intervention effects. These results suggest that reversal of lockdown, without implementation of additional, equally effective interventions, will enable continued, sustained transmission of SARS-CoV-2 in the United States.

Our study has several limitations. First, the assumption that all interventions have the same implementation and effect in all states is a strong assumption. For example, states with a stronger culture of recreational sports will likely see a greater impact of the sports intervention than states without that culture. More directly, the intervention banning public gatherings of 100 persons or more could be met by a ban on 10 persons or more or 50 persons or more; it is unlikely that such bans are truly equivalent. This limitation has since been partially addressed in the European model by allowing random effects for lockdown only. Second, the assumption that interventions are binary rather than continuously varying is also a strong assumption and clearly an oversimplification, because it does not account for time-varying compliance with intervention. Several groups are incorporating mobility data as a measure of population mixing (Unwin et al., 2020; Woody et al., 2020; Team and Murray, 2020). Third, the parameters of the model are estimated using reasonable, but still uncertain, assumptions about prior distributions. We have used the same assumptions as in the European model, but these assumptions may be contradicted by future empirical work.

Modeling of SARS-CoV-2 is emerging and rapidly diversifying, including classical SEIR models and derivatives (Pei and Shaman, 2020), deep learning (Prakash, 2020), and piecewise models for sub-exponential growth (Scire et al., 2020). State and local governments are likewise rapidly adjusting their policy decisions regarding interventions based on case data and economic concerns. As the United States adopts an increasingly fragmented response to SARSCoV-2, modeling approaches like ours that focus on shared interventions may not be tenable. While our results give valuable insights into which interventions did and which did not change the transmission rate substantially, we recommend that future studies measure the change in behaviors resulting from interventions and then strengthen the predictive relationships between these behaviors and disease transmission.

\section{REFERENCES}

Yan Bai, Lingsheng Yao, Tao Wei, Fei Tian, Dong-Yan Jin, Lijuan Chen, and Meiyun Wang. 2020. Presumed Asymptomatic Carrier Transmission of COVID-19. JAMA 323, 14 (2020), 1406-1407. DOI: http://dx.doi.org/10.1001/jama.2020.2565

Lydia Bourouiba. 2020. Turbulent Gas Clouds and Respiratory Pathogen Emissions: Potential Implica- 
tions for Reducing Transmission of COVID-19. JAMA (2020). DOI : http://dx . doi .org/10 . 1001 / jama.2020.4756

Bob Carpenter, Andrew Gelman, Matthew Hoffman, Daniel Lee, Ben Goodrich, Michael Betancourt, Marcus Brubaker, Jiqiang Guo, Peter Li, and Allen Riddell. 2017. Stan: A Probabilistic Programming Language. Journal of Statistical Software, Articles 76, 1 (2017), 1-32. DOI : http://dx.doi . org/10.18637/jss.v076.i01

Neil Ferguson, Daniel Laydon, Gemma Nedjati Gilani, Natsuko Imai, Kylie Ainslie, Marc Baguelin, Sangeeta Bhatia, Adhiratha Boonyasiri, ZULMA Cucunuba Perez, and Gina Cuomo-Dannenburg. 2020. Impact of non-pharmaceutical interventions (NPIs) to reduce COVID19 mortality and healthcare demand. techreport 9. Imperial College London. https://www.imperial.ac.uk/mrc-global-infectious-disease-analysis/ covid-19/report-9-impact-of-npis-on-covid-19/

Seth Flaxman, Swapnil Mishra, Axel Gandy, H Unwin, $\mathrm{H}$ Coupland, $\mathrm{T}$ Mellan, $\mathrm{H}$ Zhu, T Berah, J Eaton, P Perez Guzman, and others. 2020a. Estimating the number of infections and the impact of non-pharmaceutical interventions on COVID-19 in 11 European countries. techreport 13. Imperial College London. https://www . imperial.ac.uk/mrc-global-infectious-disease-analysis/covid-19/ report-13-europe-npi-impact/

Seth Flaxman, Swapnil Mishra, Axel Gandy, H. Juliette T. Unwin, Thomas A. Mellan, Helen Coupland, Charles Whittaker, Harrison Zhu, Tresnia Berah, Jeffrey W. Eaton, Mlodie Monod, Azra C. Ghani, Christl A. Donnelly, Steven M. Riley, Michaela A. C. Vollmer, Neil M. Ferguson, Lucy C. Okell, and Samir Bhatt. 2020b. Estimating the effects of non-pharmaceutical interventions on COVID-19 in Europe. Nature (2020), 1-8. DOI : http://dx.doi .org/10.1038/s41586-020-2405-7 Publisher: Nature Publishing Group.

Nathan W. Furukawa, John T. Brooks, and Jeremy Sobel. 2020. Early Release - Evidence Supporting Transmission of Severe Acute Respiratory Syndrome Coronavirus 2 While Presymptomatic or Asymptomatic. Emerging Infectious Diseases 26, 7 (7 2020). DOI : http://dx. doi .org/10. $3201 /$ eid2607.201595

Wei-jie Guan, Zheng-yi Ni, Yu Hu, Wen-hua Liang, Chun-quan Ou, Jian-xing He, Lei Liu, Hong Shan, Chun-liang Lei, David S.C. Hui, Bin Du, Lan-juan Li, Guang Zeng, Kwok-Yung Yuen, Ru-chong Chen, Chun-li Tang, Tao Wang, Ping-yan Chen, Jie Xiang, Shi-yue Li, Jin-lin Wang, Zi-jing Liang, Yi-xiang Peng, Li Wei, Yong Liu, Ya-hua Hu, Peng Peng, Jian-ming Wang, Ji-yang Liu, Zhong Chen, Gang Li, Zhi-jian Zheng, Shao-qin Qiu, Jie Luo, Chang-jiang Ye, Shao-yong Zhu, and Nan-shan Zhong. 2020. Clinical Characteristics of Coronavirus Disease 2019 in China. New England Journal of Medicine 382, 18 (2020), 1708-1720. DOI : http://dx . doi .org/10.1056/ NEJMoa2002032

C.R. Horsburgh and B.E. Mahon. 2008. Infectious Disease Epidemiology. In Modern epidemiology (3 ed.), Kenneth J. Rothman, Sander Greenland, and Timothy L. Lash (Eds.). Lippincott Williams \& Wilkins, Chapter 27.

Andrew M. Olney and Rachel C. Olney. 2020. US State Social Distancing Intervention Dates (valid to 4/25/20). (2020). DOI:http://dx.doi.org/10.5281/zenodo.3901617

Sen Pei and Jeffrey Shaman. 2020. Initial Simulation of SARS-CoV2 Spread and Intervention Effects in the Continental US. medRxiv (2020), 2020.03.21.20040303. DOI : http: / / dx. doi . org/ 10 . $1101 / 2020.03 .21 .20040303$

Jason Phua, Li Weng, Lowell Ling, Moritoki Egi, Chae-Man Lim, Jigeeshu Vasishtha Divatia, Babu Raja Shrestha, Yaseen M. Arabi, Jensen Ng, Charles D. Gomersall, Masaji Nishimura, Younsuck Koh, 
and Bin Du. 2020. Intensive care management of coronavirus disease 2019 (COVID-19): challenges and recommendations. The Lancet Respiratory Medicine 8, 5 (2020), 506-517. DOI : http: / / dx . doi.org/10.1016/s2213-2600(20)30161-2

B. Aditya Prakash. 2020. Forecasting the COVID-19 trajectory. (2020). https : / www . cc . gatech . edu/ badityap/covid.html

Jeremie Scire, Sarah Nadeau, Timothy Vaughan, Gavin Brupbacher, Simon Fuchs, Jrg Sommer, Katrin N. Koch, Reto Misteli, Lukas Mundorff, Thomas Gtz, Tobias Eichenberger, Carlos Quinto, Miodrag Savic, Andrea Meienberg, Thilo Burkard, Michael Mayr, Christoph A Meier, Andreas Widmer, Richard Kuehl, Adrian Egli, Hans H Hirsch, Stefano Bassetti, Christian H Nickel, Katharina S Rentsch, Werner Kbler, Roland Bingisser, Manuel Battegay, Sarah Tschudin-Sutter, and Tanja Stadler. 2020. Reproductive number of the COVID-19 epidemic in Switzerland with a focus on the Cantons of Basel-Stadt and Basel-Landschaft. Swiss Medical Weekly (2020). DOI: http://dx.doi.org/10.4414/smw.2020.20271

IHME COVID-19 health service utilization forecasting Team and Christopher JL Murray. 2020. Forecasting the impact of the first wave of the COVID-19 pandemic on hospital demand and deaths for the USA and European Economic Area countries. medRxiv (2020), 2020.04.21.20074732. DOI: http://dx.doi.org/10.1101/2020.04.21.20074732

The New York Times. 2020. nytimes/covid-19-data. (2020). https://github.com/nytimes/ covid-19-data original-date: 2020-03-24T23:41:39Z.

H Juliette T Unwin, Swapnil Mishra, Valerie C Bradley, Axel Gandy, Michaela Vollmer, Thomas Mellan, Helen Coupland, Kylie Ainslie, Charlie Whittaker, Jonathan Ish-Horowicz, Sarah Filippi, Xiaoyue Xi, Melodie Monod, Oliver Ratmann, Michael Hutchinson, Fabian Valka, Harrison Zhu, Iwona Hawryluk, Philip Milton, Marc Baguelin, Adhiratha Boonyasiri, Nick Brazeau, Lorenzo Cattarino, Giovanni Charles, Laura V Cooper, Zulma Cucunuba, Gina Cuomo-Dannenburg, Bimandra Djaafara, Ilaria Dorigatti, Oliver J Eales, Jeff Eaton, Sabine van Elsland, Richard FitzJohn, Katy Gaythorpe, William Green, Timothy Hallett, Wes Hinsley, Natsuko Imai, Ben Jeffrey, Edward Knock, Daniel Laydon, John Lees, Gemma Nedjati-Gilani, Pierre Nouvellet, Lucy Okell, Alison Ower, Kris V Parag, Igor Siveroni, Hayley A Thompson, Robert Verity, Patrick Walker, Caroline Walters, Yuanrong Wang, Oliver J Watson, Lilith Whittles, Azra Ghani, Neil M Ferguson, Steven Riley, Christl A. Donnelly, Samir Bhatt, and Seth Flaxman. 2020. Report 23 - State-level tracking of COVID-19 in the United States. techreport 23. Imperial College London. http://www.imperial.ac.uk/medicine/ departments/school-public-health/infectious-disease-epidemiology/ mrc-global-infectious-disease-analysis/covid-19/ report-23-united-states/ Library Catalog: www.imperial.ac.uk.

U.S. Census Bureau. 2020. ACS Demographic and Housing Estimates. (2020). https://data. census.gov/cedsci/table? q=acs\&tid=ACSDP 5Y2018.DP 05 \& vintage=2018

Neeltje van Doremalen, Trenton Bushmaker, Dylan H. Morris, Myndi G. Holbrook, Amandine Gamble, Brandi N. Williamson, Azaibi Tamin, Jennifer L. Harcourt, Natalie J. Thornburg, Susan I. Gerber, James O. Lloyd-Smith, Emmie de Wit, and Vincent J. Munster. 2020. Aerosol and Surface Stability of SARS-CoV-2 as Compared with SARS-CoV-1. New England Journal of Medicine 382, 16 (2020), 1564-1567. DOI: http://dx.doi.org/10.1056/NEJMc2004973

Robert Verity, Lucy C. Okell, Ilaria Dorigatti, Peter Winskill, Charles Whittaker, Natsuko Imai, Gina Cuomo-Dannenburg, Hayley Thompson, Patrick Walker, Han Fu, Amy Dighe, Jamie Griffin, Anne Cori, Marc Baguelin, Sangeeta Bhatia, Adhiratha Boonyasiri, Zulma M. Cucunuba, Rich Fitzjohn, Katy A. M. Gaythorpe, Will Green, Arran Hamlet, Wes Hinsley, Daniel Laydon, Gemma NedjatiGilani, Steven Riley, Sabine van Elsand, Erik Volz, Haowei Wang, Yuanrong Wang, Xiayoue Xi, 
medRxiv preprint doi: https://doi.org/10.1101/2020.07.10.20151001; this version posted July 11, 2020. The copyright holder for this preprint

(which was not certified by peer review) is the author/funder, who has granted medRxiv a license to display the preprint in perpetuity.

It is made available under a CC-BY-NC-ND 4.0 International license.

Christl Donnelly, Azra Ghani, and Neil Ferguson. 2020. Estimates of the severity of COVID-19 disease. medRxiv (2020), 2020.03.09.20033357. DOI:http://dx.doi.org/10.1101/2020. 03.09 .20033357

Spencer Woody, Mauricio Garcia Tec, Maytal Dahan, Kelly Gaither, Michael Lachmann, Spencer Fox, Lauren Ancel Meyers, and James G. Scott. 2020. Projections for first-wave COVID-19 deaths across the US using social-distancing measures derived from mobile phones. medRxiv (2020), 2020.04.16.20068163. DOI : http://dx.doi.org/10.1101/2020.04.16.20068163 